\title{
The rise of the invasives and decline of the natives: insights revealed from adult populations of container-inhabiting Aedes mosquitoes (Diptera: Culicidae) in temperate North America
}

\author{
Ilia Rochlin • Randy Gaugler • Eric Williges • \\ Ary Farajollahi
}

Received: 4 June 2012/ Accepted: 10 October 2012/Published online: 23 October 2012

(C) The Author(s) 2012. This article is published with open access at Springerlink.com

\begin{abstract}
Container-inhabiting Aedes mosquitoes are successful invaders and important arthropod-borne disease vectors worldwide. In North America, a subtropical assemblage containing introduced Aedes albopictus and Aedes aegypti and the native Aedes triseriatus have served as a model for investigating ecological interactions during invasions and focused on the outcomes at the larval stages. We report a hypothesis driven study of a more temperate container Aedes assemblage at the adult population level monitored in the state of New Jersey during a 9-year period. The invasive A. albopictus and Aedes japonicus abundances increased by a factor of two, whereas A. triseriatus abundance decreased by a factor of three. Spatiotemporal analysis indicated these trends were coincident especially in the areas invaded by $A$. albopictus, leading to partial displacement of
\end{abstract}

\section{Rochlin}

Division of Vector Control,

Suffolk County Department

of Public Works, Yaphank, NY, USA

R. Gaugler · E. Williges · A. Farajollahi $(\square)$

Center for Vector Biology, Rutgers University,

180 Jones Avenue, New Brunswick, NJ 08901, USA

e-mail: farajoll@rci.rutgers.edu

E. Williges

Essex County Division of Mosquito Control,

Cedar Grove, NJ, USA

\section{A. Farajollahi}

Mercer County Mosquito Control, West Trenton,

NJ, USA
A. triseriatus. Although the invasive species reached peak abundance in highly urbanized areas, the native species' rate of decline was similar across the urbanization gradient. Higher winter temperatures and precipitation favored increased A. albopictus abundance suppressing A. triseriatus adult populations in turn, whereas A. japonicus abundance was promoted by summer precipitation. The results validate the conceptual framework developed for subtropical container Aedes and suggest that the current climatic trends will favor further spread of $A$. albopictus, amplifying public health concerns.

Keywords Competitive displacement - Invasive species - Interspecies competition - Urbanization · Public health

\section{Introduction}

Container- or tree hole-inhabiting mosquitoes from the genus Aedes have been intensively studied over several decades for a variety of reasons. From an ecological perspective, these mosquitoes and their preferred habitat (artificial containers or tree holes) provide a simple system for studying complex problems of species interactions, trophic processes, and community structure (Juliano 1998, 2009; Ellis et al. 2006). From an invasion biology perspective, container Aedes represent a model for one of the most 
successful invasive species on the planet (Juliano 1998; Lounibos 2002). From a public health perspective, these mosquitos are of exceptional importance as vectors of rapidly spreading or "re-emerging" pathogens such as dengue, chikungunya, yellow fever, West Nile, and other arboviruses (reviewed in Lounibos 2002; Juliano and Lounibos 2005; Weaver and Reisen 2010).

Among container Aedes, the Asian tiger mosquito, Aedes albopictus (Skuse), has figured prominently as a research subject due to high invasion potential illustrated through global spread, competitive larval advantages over other container Aedes, and the ability to vector numerous pathogens (Lounibos 2002; Juliano and Lounibos 2005). Shortly after A. albopictus invaded North America in the 1980's, it was predicted to partially displace the native tree hole mosquito Aedes triseriatus (Coquillett) (Livdahl and Willey 1991). However, the number of field investigations studying these interactions have been relatively small and only scant evidence of the predicted outcomes have been presented (Lounibos et al. 2001; Juliano 2009).

The subtropical container Aedes assemblage in Florida, which consists of A. albopictus, A. triseriatus, and another invasive species, Aedes aegypti (L.), is the best described (Ho et al. 1989; Edgerly et al. 1999; Lounibos et al. 2001; Ellis et al. 2006; Juliano 2009). However, A. aegypti is not found in much of the eastern USA, where the Asian bush mosquito Aedes japonicus (Theobald), a recently introduced species which has not been adequately characterized from an ecological standpoint, is a common member of a temperate container Aedes assemblage (Peyton et al. 1999). For both assemblages, competitive asymmetry among larval stages appears to be the main force driving container Aedes population dynamics (Juliano 2009). Although the mechanisms of such species interactions have been well investigated experimentally, the impacts of such interactions on populations in nature remains uncertain (Lounibos et al. 2001; Juliano 2009). This may be due to lack of data on effects on the adults of these species, despite the importance of such information for both ecological theory and public health.

While previous studies concentrated on larval interactions and were primarily conducted in warmer climates, our analyses focus on adult populations within a temperate environment, coinciding with the northernmost distribution of A. albopictus along the USA eastern seaboard (Farajollahi and Nelder 2009).
Long-term population trends and large-scale spatial dynamics of adult A. albopictus, A. japonicus, and A. triseriatus assemblage in eastern USA were examined in view of the following hypotheses. (1) A. albopictus is a stronger larval competitor and would displace the native A. triseriatus with some exceptions, see hypothesis \#3 (Livdahl and Willey 1991; Novak et al. 1993; Teng and Apperson 2000; Lounibos et al. 2001); (2) A. japonicus is an inferior larval competitor to A. albopictus and a superior larval competitor to A. triseriatus (Armistead et al. 2008; Andreadis and Wolfe 2010; Alto 2011) resulting in similarly detectable trends in the adult populations; (3) A. triseriatus displacement trends are context-dependent with urban areas experiencing sharper declines compared to less disturbed rural environments (Livdahl and Willey 1991, Lounibos et al. 2001); (4) interactions among these species will be dependent on climatic conditions, with warmer temperatures generally favoring larval A. albopictus (Hanson and Craig 1995; Teng and Apperson 2000; Armistead et al. 2008), translating into increased adult population growth for this species.

\section{Materials and methods}

Study area, duration, and data sources

Mosquitoes were collected at 4,230 total trap sites throughout the state of New Jersey, USA during 2002-2010. Dry ice-baited CDC light traps and gravid traps with grass infusion were employed from May through October during each year to collect female mosquitoes. Due to similar patterns, data from CDC light and gravid traps were combined to reduce potential bias and to increase the power of analysis.

The urban areas shapefile were obtained from the Census Bureau (www.census.gov/geo/www/tiger/ tigerua/ua_tgr2k.html). The Census Bureau's urban areas represent densely developed territory with a population of 50,000 or more and encompass residential, commercial, and other non-residential urban land uses. Outside of these areas, territory containing at least 2,500 but less than 50,000 people is also considered urbanized (i.e. urban clusters). Rural areas are defined as any territory outside urban areas. Climatological data and long term trends were obtained from the Office of the New Jersey State Climatologist 
at Rutgers University (http://climate.rutgers.edu/ stateclim_v1/data).

\section{Statistical analysis}

The state of New Jersey was overlaid with $10 \times 10 \mathrm{~km}$ grid and the cells were used as the spatial unit of analysis. Grid cells without traps in either 2002-2004 or 2009-2010 (i.e. none or insufficient data) were eliminated, resulting in 156 data cells out of 252 total and covering $61.9 \%$ of the state area. Trap count was used as a direct measure of relative adult mosquito abundance or production, representing the dependent variable in the analyses. Trap count was defined as the number of mosquitoes collected per trap per night, and averaged for all traps within each $10 \times 10 \mathrm{~km}$ grid cell for each year. The dataset summary statistics including average trap count per night, total number of mosquitoes collected, number of trap nights, and number of trapping locations in each year are presented in Table 1.

Multivariate analyses comparing the overall changes in Aedes species abundance and composition through time were performed using nonparametric methods in Permanova+/Primer v 6.0 statistical package (Primer-E Ltd, Ivybridge, UK). PERMANOVA is a nonparametric analog of MANOVA using a Bray-Curtis resemblance matrix. SIMPER (contributions of variables to similarity) was used to elucidate the role of individual species in contributing to the significant differences by PERMANOVA. If no significant differences in Aedes species abundance and composition were found, consecutive years were grouped into time periods representing early, middle, and later stages of A. albopictus and A. japonicus invasions. This analysis was followed by univariate Mann-Whitney and Chi-square tests comparing abundance and spatial occurrence, respectively, of individual Aedes species through three time periods of early, middle, and later stages of invasion.

To characterize the association between weather and adult container Aedes abundance, temperature and precipitation data were extracted for the preceding winter, spring, summer, and fall for each year in 2002-2010. Mosquito abundance for each species was then regressed against each independent climatic variable separately, followed by fitting a multivariate model including all statistically significant climatic variables. The most parsimonious model was selected using stepwise procedure in linear regression. Univariate tests and regression analyses were performed in SPSS v20.0 (IBM Corp, Armonk, NY). Multiple comparisons were Bonferroni adjusted.

Spatial analysis was performed by Spatial Analysis by Distance Indices (SADIE, http://www.rothamsted. ac.uk/pie/sadie/SADIE_home_page_1.htm) (Perry et al. 1999) following by visualization in ArcMap (ESRI, Redlands, CA). Since only integers are accepted by the software, average trap counts per cell/time period were rounded to zero decimal points. Values $>0$ but $<0.5$ were rounded to one, indicating presence. A cluster described a region of high trap counts and a gap describes a region of low trap counts at the $90 \%$ confidence interval. The statistical significance of spatial

Table 1 Summary statistics for the dataset used in this study

\begin{tabular}{|c|c|c|c|c|c|c|c|c|}
\hline \multirow[t]{2}{*}{ Years } & \multicolumn{3}{|c|}{$\begin{array}{l}\text { Number of female mosquitoes (mean } \pm \text { SE) } \\
\text { collected per trap night in each } 10 \times 10 \text { grid cell }\end{array}$} & \multicolumn{3}{|c|}{$\begin{array}{l}\text { Total number of female } \\
\text { mosquitoes collected }\end{array}$} & \multirow[t]{2}{*}{$\begin{array}{l}\text { Number of trap } \\
\text { nights }\end{array}$} & \multirow[t]{2}{*}{$\begin{array}{l}\text { Number of trapping } \\
\text { locations }\end{array}$} \\
\hline & A & $\mathrm{J}$ & $\mathrm{T}$ & A & $\mathrm{J}$ & $\mathrm{T}$ & & \\
\hline 2002 & $1.57 \pm 0.67$ & $0.91 \pm 0.12$ & $2.16 \pm 0.25$ & 1,781 & 1,897 & 1,836 & 1,294 & 733 \\
\hline 2003 & $1.1 \pm 0.2$ & $2.19 \pm 0.23$ & $2.24 \pm 0.32$ & 870 & 3,008 & 2,313 & 905 & 634 \\
\hline 2004 & $1.36 \pm 0.25$ & $3.36 \pm 0.5$ & $1.86 \pm 0.48$ & 890 & 3,621 & 1,249 & 810 & 501 \\
\hline 2005 & $2.21 \pm 0.43$ & $2.5 \pm 0.28$ & $0.95 \pm 0.12$ & 2,143 & 2,569 & 900 & 905 & 526 \\
\hline 2006 & $4.09 \pm 0.6$ & $1.96 \pm 0.31$ & $0.79 \pm 0.2$ & 2,836 & 1,519 & 430 & 746 & 483 \\
\hline 2007 & $2.98 \pm 0.32$ & $2.18 \pm 0.26$ & $0.87 \pm 0.39$ & 5,447 & 2,127 & 473 & 1,132 & 536 \\
\hline 2008 & $4.9 \pm 0.53$ & $1.64 \pm 0.27$ & $0.49 \pm 0.08$ & 6,548 & 2,309 & 672 & 1,522 & 715 \\
\hline 2009 & $3.04 \pm 0.45$ & $4.33 \pm 0.54$ & $0.94 \pm 0.14$ & 4,199 & 5,033 & 1,162 & 1,398 & 677 \\
\hline 2010 & $4.07 \pm 0.46$ & $1.55 \pm 0.22$ & $0.44 \pm 0.09$ & 3,528 & 1,757 & 375 & 1,039 & 592 \\
\hline
\end{tabular}


association analysis between two species was assessed by a randomization test with a $75 \%$ confidence interval used due to the overly stringent correction for spatial autocorrelation in the software.

\section{Results}

Temporal patterns in the container Aedes adult populations

\section{A. albopictus is a stronger larval competitor and} would displace the native A. triseriatus

Container Aedes abundance and composition experienced significant changes over the study period, PERMANOVA pseudo- $\mathrm{F}_{8,1559}=19.3, \quad p<0.001$ (Fig. 1). The baseline year 2002 was different from all other years at Bonferroni adjusted $p<0.0014$. Years 2003-2005 (middle stages of invasion) and years 2006-2010 (later stages of invasion) formed relatively homogeneous subsets and were grouped as two time periods. Thus, the following analyses were conducted on the three time periods: 2002 represented the early stage, 2003-2005 represented the middle stage, and 2006-2010 represented the later stage of A. albopictus and A. japonicus invasions.

Between 2002 and 2003-2005 time periods, A. japonicus abundance increased and A. triseriatus decreased, whereas A. albopictus abundance remained similar (Table 2). In contrast, the changes between 2003-2005 and 2006-2010 time periods were characterized by a significant increase in $A$. albopictus abundance, and a decline in A. japonicus and $A$. triseriatus. Compared to the baseline year 2002, A. albopictus and A. japonicus

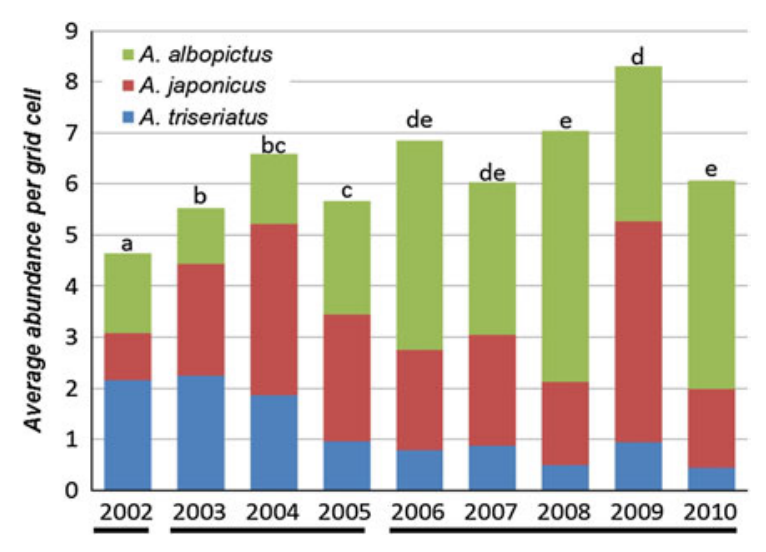

Fig. 1 Container Aedes abundance (Y-axis, season average per trap night in a grid cell) and species composition by year. Different letters indicate significant difference at Bonferroni adjusted $p<0.0014$ by pairwise PERMANOVA comparisons. Combined time periods for the analysis are underlined. The year 2002 was the baseline for the early stage of A. albopictus and A. japonicus invasions. The years 2003-2005 were grouped in the subsequent analysis as the middle stage of invasion. The years 2006-2010 were grouped in the subsequent analysis as the later stage of invasion

abundances increased by more than a factor of two, whereas A. triseriatus abundance declined by more than a factor of three during the late stage of invasion in the 2006-2010 time period. These differences among the three time periods were statistically significant overall, PERMANOVA pseudo- $\mathrm{F}_{2,1565}=60.8, p<0.0001$, and when compared to each other at $p<0.0001$.

A. japonicus is an inferior larval competitor to

A. albopictus and a superior larval competitor to

A. triseriatus, resulting in detectable trends in adult populations

Temporal changes in container Aedes abundance may have occurred due to shifts in production (i.e.

Table 2 Temporal changes in container Aedes species abundance through different stages of A. albopictus, and A. japonicus invasions

\begin{tabular}{|c|c|c|c|c|c|c|}
\hline \multirow[t]{2}{*}{ Aedes spp } & \multicolumn{3}{|c|}{ Average trap night collection within a $10 \times 10 \mathrm{~km}$ grid cell $* *$} & \multicolumn{3}{|c|}{ SIMPER contributions to significant differences*** } \\
\hline & $2002(\mathrm{E})$ & 2003-2005 (M) & 2006-2010 (L) & $\mathrm{E}-\mathrm{M}(\%)$ & M-L (\%) & E-L (\%) \\
\hline A & $1.57^{\mathrm{a}}$ & $1.52^{\mathrm{a}}$ & $3.84^{\mathrm{b}}$ & 27 & 42 & 43 \\
\hline $\mathrm{J}$ & $0.91^{\mathrm{a}}$ & $2.66^{\mathrm{b}}$ & $2.32^{\mathrm{c}}$ & 39 & 38 & 30 \\
\hline $\mathrm{T}$ & $2.16^{\mathrm{a}}$ & $1.73^{\mathrm{b}}$ & $0.7^{\mathrm{c}}$ & 34 & 20 & 27 \\
\hline
\end{tabular}

A, A. albopictus; J, A. japonicus; T, A. triseriatus

** Overall PERMANOVA pseudo-F $2,1565=60.8, p<0.0001$. Different letters indicate statistically significant differences in species abundances (in rows) by Mann-Whitney test at $p<0.001$

*** Stages of A. albopictus, and A. japonicus invasions: E-early (2002); M-middle (2003-2005); L-late (2006-2010). All pairwise comparisons significant at $p<0.0001$ by PERMANOVA 
changes in the number of mosquitoes collected in traps excluding all zero catch traps for this particular species), alterations in the spatial distribution (i.e. changes in the number of grid cells where the species was collected), or both. For A. albopictus, production remained comparable in 2002 and 2003-2005 time periods, but increased significantly by about $1 / 3$ in 2006-2010 time period (Table 3). Similarly, this species occupied about $40 \%$ of the grid cells in the 2002 and 2003-2005 time periods before a significant increase to about $70 \%$ in the 2006-2010 time periods. For $A$. triseriatus, the trends were the opposite, with production similar in 2002 and 2003-2005 time periods followed by about a $40 \%$ decrease in 2006-2010 time period. The decline in spatial distribution of this species continued from almost $90 \%$ of the grid cells in 2002 , to about $70 \%$ in 2003-2005 time period, to just over $50 \%$ in 2006-2010 time period. Aedes japonicus production peaked in 2003-2005 time period, and slightly declined in 2006-2010 time period to levels comparable with those at the baseline time period of 2002. The spatial distribution of this species experienced similar trends, significantly increasing from about $60 \%$ of the grid cells in 2002 to close to $85 \%$ in 2003-2005 time period before a slight decline to $80 \%$ during 2006-2010 time period.

Spatial patterns in the container Aedes adult populations

A. albopictus was a stronger larval competitor and displaced the native A. triseriatus, detectable at the adult population level
In general, SADIE analysis indicated considerable temporal changes in spatial structure for A. albopictus and $A$. triseriatus, but much less so for A. japonicus (Fig. 2). In 2002, clusters of high counts for all three species were spatially segregated, with high A. albopictus counts found mostly in the Philadelphia-Trenton metro area. In 2003-2005 time period, A. albopictus clusters expanded into the southern half of the state, where high $A$. triseriatus clusters detected in 2002 were becoming significantly lower. During 2006-2010 time period, high counts and A. albopictus clustering in the southern and coastal areas of New Jersey expanded and became more pronounced. For A. triseriatus, the spatial structure became significant once again, but nearly in reverse from that in 2002, i.e. clusters in the north with gaps in the south and along the coast. For A. japonicus, strong clusters were found in the northern part of the state throughout the study period, but gaps (i.e. low counts) strengthened along the coast and in the south, especially noticeable between 2003-2005 and 2006-2010 time periods.

A. japonicus was an inferior larval competitor to

A. albopictus and a superior larval competitor to

A. triseriatus, resulting in detectable trends in the adult populations

Comparison of the association of each species pair through time (Fig. 3) revealed that A. albopictus and A. triseriatus negative associations (i.e. high vs. low counts) progressed from the highly urbanized metro areas in 2002, to scattered throughout the state in 2003-2005 time period (transition), to the entire southern and coastal regions in 2006-2010 time period,

Table 3 Temporal changes in container Aedes production and spatial distribution through different stages of A. albopictus, and A. japonicus invasions

\begin{tabular}{|c|c|c|c|c|c|c|}
\hline \multirow[t]{2}{*}{ Aedes spp } & \multicolumn{2}{|l|}{2002 (Early) } & \multicolumn{2}{|c|}{ 2003-2005 (Middle) } & \multicolumn{2}{|l|}{ 2006-2010 (Late) } \\
\hline & Avg. production** & $\%$ Grid cells $* * *$ & Avg. production & $\%$ Grid cells & Avg. production & $\%$ grid cells \\
\hline A & $4.74^{\mathrm{a}}$ & $36(-)$ & $3.79^{\mathrm{a}}$ & $43(-)$ & $5.27^{\mathrm{b}}$ & $72(+)$ \\
\hline $\mathrm{J}$ & $1.98^{\mathrm{a}}$ & $59(-)$ & $3.71^{\mathrm{b}}$ & 84 & $3.47^{\mathrm{a}}$ & 80 \\
\hline $\mathrm{T}$ & $2.56^{\mathrm{a}}$ & $89(+)$ & $2.54^{\mathrm{a}}$ & $73(+)$ & $1.5^{\mathrm{b}}$ & $53(-)$ \\
\hline
\end{tabular}

A, A. albopictus; J, A. japonicus; T, A. triseriatus

** Average production, i.e. the average trap night collections in each $10 \times 10 \mathrm{~km}$ grid cell excluding all zero traps where the particular species was not found. Different letters indicate statistically significant differences in individual species average production (rows) by Mann-Whitney test at $p \leq 0.001$

*** Percent of $10 \times 10 \mathrm{~km}$ grid cells where the species was collected. (-) indicates smaller proportion of cells where the species was found than that expected by chance, Chi-square test z-score $<-2.0, p<0.001$. ( + ) indicates larger proportion of cells where the species was found than that expected by chance, Chi-square test z-score $>2.0, p<0.001$ 

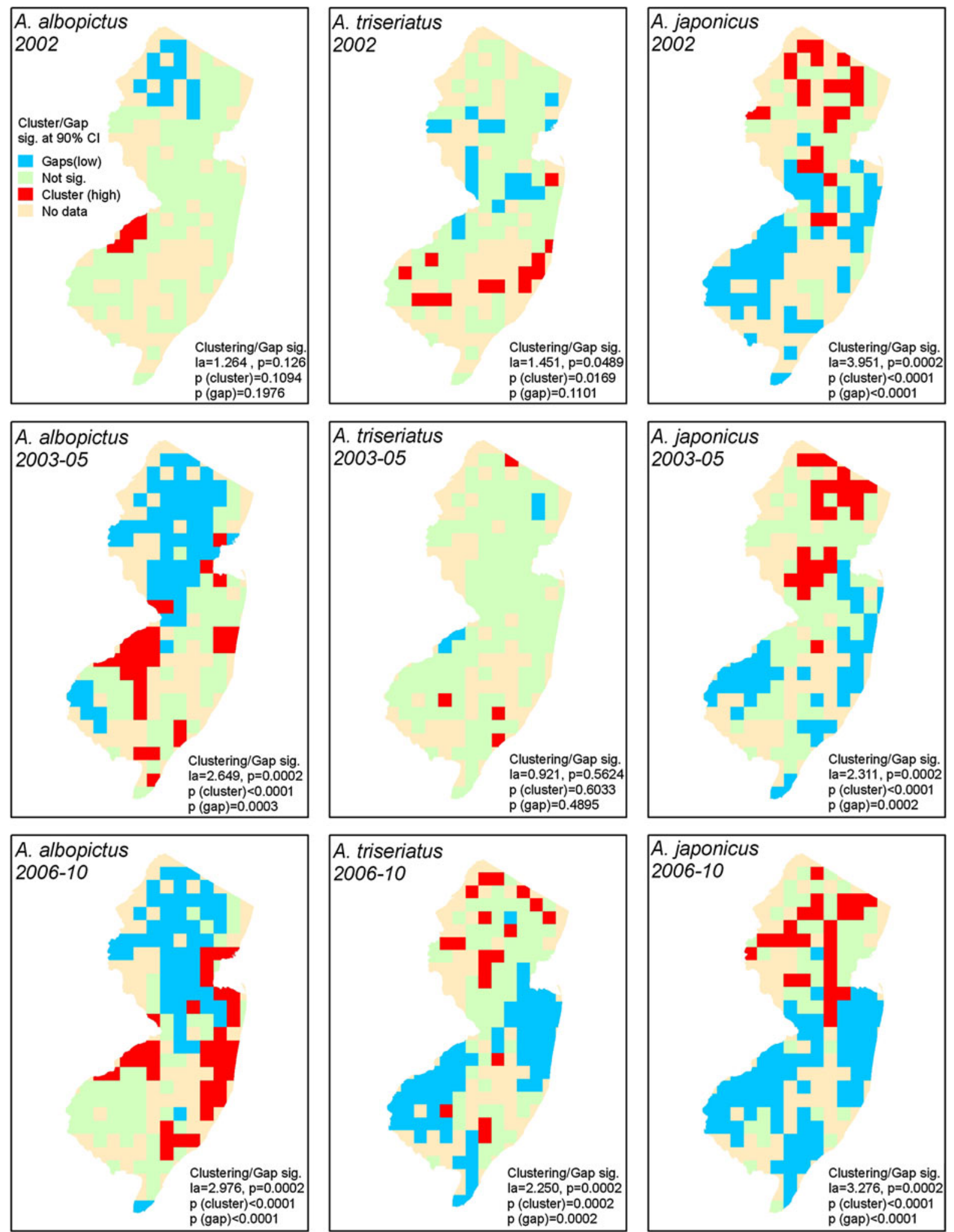
4 Fig. 2 SADIE analysis of spatial clustering of A. albopictus, A. triseriatus, and A. japonicus trap counts. The species and the time period are indicated on the maps. Overall statistical significance, and cluster/gap statistical significance are shown. Significant grid cells forming clusters (red) and gaps (blue) correspond to $90 \%$ confidence interval. Non-significant clusters are shown in light green (Color figure online)

with only two grid cells displaying significant positive associations (i.e. high vs. high counts). The negative associations of A. albopictus-A. japonicus followed the same pattern of expansion, although it was less evident because most $A$. japonicus clusters were detected in the northern part of the state. Only one grid cell with significant positive association (i.e. high vs. high counts) in 2006-2010 time period was detected. Prior to $A$. albopictus expansion, $A$. japonicus- $A$. triseriatus negative associations were spatially segregated in the north and the south, respectively. As A. triseriatus high counts in the southern and coastal regions continued to decrease during 2003-2010 time period, more grid cells in the north that were originally non-significant or low were becoming high clusters relative to the rest of the state. As a result, most of the A. triseriatus significant associations (both negative and positive) were found in the north by 2006-2010 time period. More cells $(\mathrm{n}=7)$ with a positive association between A. japonicus-A. triseriatus were detected compared to the pairing of each of those species with A. albopictus.

Adult container Aedes spatiotemporal trends along the urbanization gradient

A. triseriatus displacement trends were contextdependent with urban areas experiencing sharper declines compared to less disturbed rural environments

To elucidate whether the observed changes in container Aedes species abundance were contextdependent on the degree of urbanization, percent of urban area by the Census Bureau was calculated for each grid cell, and the dataset subdivided into quartiles. Both urbanization (pseudo- $\mathrm{F}_{3,1556}=4.0, p<0.0001$ ) and time period (pseudo- $\mathrm{F}_{2,1556}=61.2, p<0.0001$ ) were significant, whereas their interaction term was not (pseudo- $\mathrm{F}_{6,1556}=1.3, p=0.1394$ ) in a full PERMANOVA model. The spatial differences among urbanization quartiles were mostly due to increased abundances of A. albopictus and, to a lesser degree, those of A. japonicus with increased urbanization (Table 4; SIMPER, data not shown). For both species, the most urbanized areas $(>75 \%)$ contained the highest average abundance. By contrast, A. triseriatus was the most abundant in rural areas $(<25 \%$ urbanization) followed by highly urbanized areas, with the lowest relative abundance in suburban areas (25-75\% urbanization). Although these general trends persisted throughout the study period, the largest increases in A. albopictus and the corresponding decreases in A. triseriatus populations occurred in less urbanized areas $(<50 \%)$, whereas the largest increases of A. japonicus occurred in highly urban areas $(>75 \%)$.

Effects of climatic factors on container Aedes adult population trends

\section{Interactions among container Aedes were depen- dent on climatic conditions, with warmer tempera- tures generally favoring larval A. albopictus and growth of the adult populations of this species}

Over the study period, only A. japonicus abundance displayed consistently significant positive associations with summer precipitation and negative associations with summer temperature (Table 5). Only the former remained significant in a multiple regression explaining $45.8 \%$ of the variance. Further examinations of the data revealed that the winter of 2002 was the warmest since 1896. Additionally, 2002 had low A. albopictus abundance because this species was still expanding its range in the state at that time (Farajollahi and Nelder 2009). After 2002 was removed as an outlier, A. albopictus abundance was positively associated with winter temperature, and also with winter precipitation in the multiple regression model explaining $95.5 \%$ of the variance (Table 5). Aedes triseriatus abundance exhibited an opposite trend and was negatively associated with winter temperature and precipitation, explaining $88.0 \%$ of the variance.

\section{Discussion}

Container Aedes assemblages serve as an influential model for studying interactions among the community members, allowing for hypothesis testing in laboratory and field settings (Juliano 2009). However, knowledge gaps concerning the lack of data on the effects of larval 

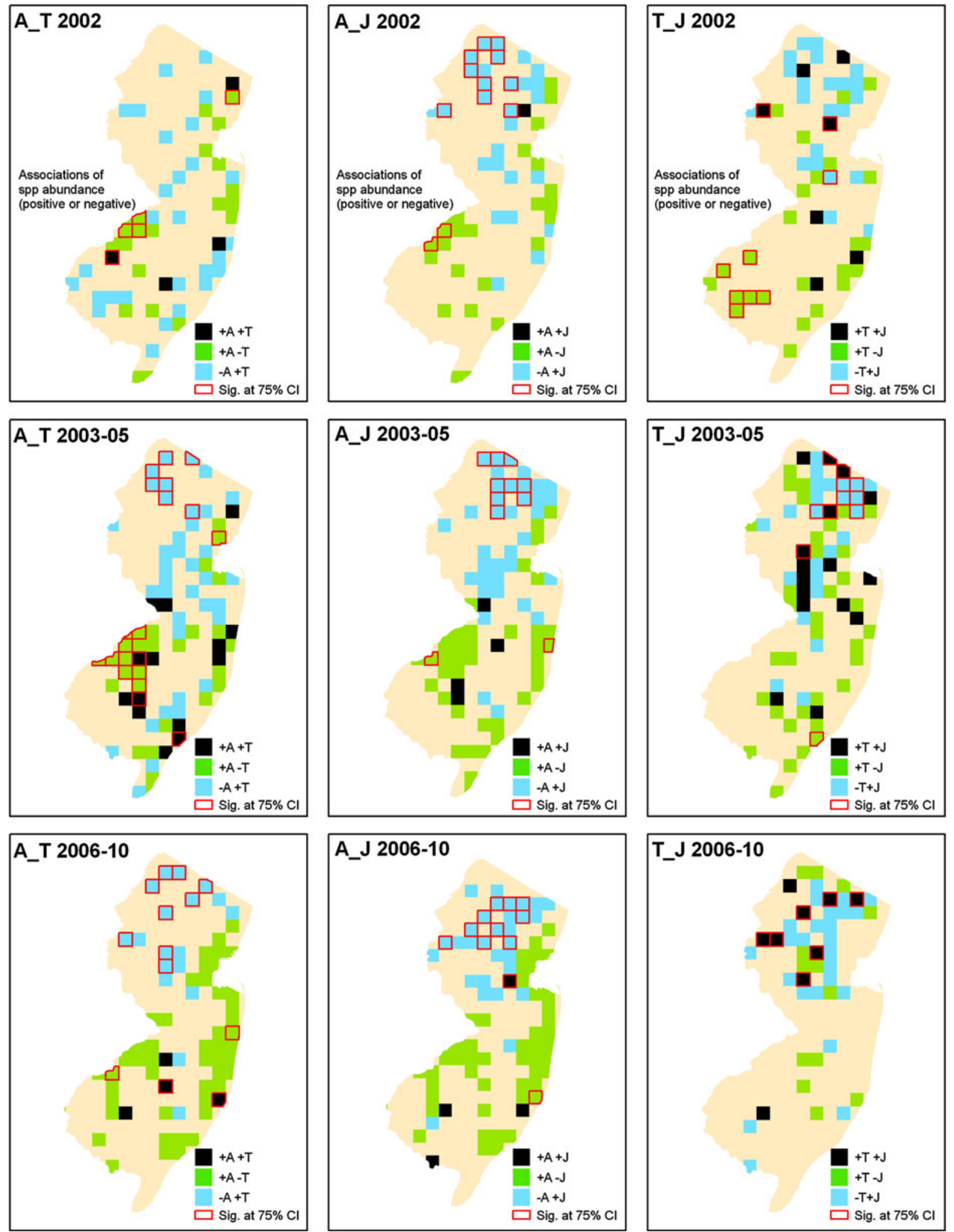
Fig. 3 SADIE analysis of spatial association between the pair of species (A, A. albopictus; J, A. japonicus; T, A. triseriatus) within the time period indicated on the map. Positive (+high abundance/+high abundance, black squares) and negative (+high abundance/-low abundance, green squares; or -low abundance/+high abundance, blue squares) associations between each pair of species are shown. Grid cells with significant associations at $75 \%$ confidence interval are indicated by red margins (Color figure online) interactions on the adult populations, scant number of field studies examining those effects, and insufficient understanding of temperate container Aedes assemblage ecology remain unresolved (Lounibos et al. 2001; Juliano 2009). The aim of the present study, therefore, was to evaluate adult container Aedes population trends over large spatial and temporal scales in temperate North America within the

Table 4 The effect of urbanization on container Aedes abundance through different stages of A. albopictus, and A. japonicus invasions

\begin{tabular}{lccc}
\hline Degree of urbanization* & \multicolumn{2}{l}{ Aedes species abundance** } \\
\cline { 2 - 4 } & A. albopictus average $(\mathrm{E}, \mathrm{M}, \mathrm{L})$ & A. japonicus average $(\mathrm{E}, \mathrm{M}, \mathrm{L})$ & A. triseriatus average $(\mathrm{E}, \mathrm{M}, \mathrm{L})$ \\
\hline$<25 \%^{\mathrm{a}}$ & $2.01(0.38,0.91,3.11)$ & $2.11(1.15,2.43,2.13)$ & $1.51(2.73,1.86,1.00)$ \\
$25-50 \%^{\mathrm{ab}}$ & $2.5(1.10,1.31,3.53)$ & $2.17(0.80,2.49,2.28)$ & $1.03(2.71,1.41,0.43)$ \\
$50-75 \%^{\mathrm{bc}}$ & $2.83(1.30,1.56,3.96)$ & $2.36(0.99,3.01,2.35)$ & $0.97(1.46,1.51,0.52)$ \\
$>75 \%^{\mathrm{d}}$ & $3.99(3.75,2.51,4.87)$ & $2.4(0.61,2.85,2.54)$ & $1.26(1.66,2.06,0.72)$ \\
\hline
\end{tabular}

* Percent urbanized areas (Census Bureau 2000 definition) within $10 \times 10$ grid cells. Different letters indicate statistically significant differences in Aedes species abundance and composition among the four degree of urbanization categories at Bonferroni adjusted $p<0.0083$ (pairwise PERMANOVA)

** Average abundance (trap night collections in each $10 \times 10 \mathrm{~km}$ cells) through three stages of A. albopictus, and A. japonicus invasions: E-early (2002); M-middle (2003-2005); L-late (2006-2010)

Table 5 Climatic predictors of container Aedes abundance

A, A. albopictus; J, A. japonicus; T, A. triseriatus

** Climatic predictors, i.e. temperature (TMP) and precipitation (PCP) for each winter, spring, summer, and fall entered independently (Single IV model) or entered and removed in stepwise regression (Multiple IV model) to select the best fitted parsimonious model *** Year 2002 (winter temperature outlier) removed for A. albopictus and $A$. triseriatus analysis

\begin{tabular}{|c|c|c|c|}
\hline \multirow{2}{*}{$\begin{array}{l}\text { Aedes } \\
\text { spp }\end{array}$} & \multicolumn{3}{|c|}{ Linear regression models with significant independent variables (IV)** } \\
\hline & $\begin{array}{l}\text { Single IV model all years, } \\
2002-2010\end{array}$ & $\begin{array}{l}\text { Single IV model year } \\
2003-2010^{* * *}\end{array}$ & Multiple IV model $* * *$ \\
\hline A & No significant IV & $\begin{array}{l}\text { TMP.winter } \\
(\mathrm{B}=0.467, \\
\mathrm{R}^{2}=0.567, \\
p=0.031)\end{array}$ & $\begin{array}{l}\text { TMP.winter } \\
(\mathrm{B}=0.605, p<0.001) \\
\text { PCP.winter } \\
(\mathrm{B}=1.056, p=0.001) \\
\mathrm{R}^{2}=0.955\end{array}$ \\
\hline $\mathrm{J}$ & $\begin{array}{l}\text { PCP.summer } \\
\left(\mathrm{B}=0.531, \mathrm{R}^{2}=0.458,\right. \\
\quad p=0.045) \\
\text { TMP.summer } \\
\left(\mathrm{B}=-0.446, \mathrm{R}^{2}=0.438,\right. \\
\quad p=0.052)\end{array}$ & No significant IV & $\begin{array}{l}\text { PCP.summer } \\
(\mathrm{B}=0.531, p=0.045) \\
\mathrm{R}^{2}=0.458\end{array}$ \\
\hline $\mathrm{T}$ & No significant IV & $\begin{array}{l}\text { TMP.winter } \\
(\mathrm{B}=-0.230 \\
\mathrm{R}^{2}=0.618 \\
p=0.021)\end{array}$ & $\begin{array}{c}\text { TMP.winter } \\
(\mathrm{B}=-0.284 \\
p<0.002) \\
\text { PCP.winter } \\
(\mathrm{B}=-0.410 \\
p=0.021) \\
\mathrm{R}^{2}=0.880\end{array}$ \\
\hline
\end{tabular}


framework of four hypotheses grounded in the experiments and observations at the larval stage.

The seminal study by (Livdahl and Willey 1991) predicted that introduced A. albopictus would competitively displace native $A$. triseriatus mosquitoes in most areas of sympatry, but a more stable coexistence would develop in tree-hole communities compared to artificial containers. Further investigations revealed that this outcome was context-dependent and densitymediated. The competitive advantage of A. albopictus was enhanced under scarce food resources (Novak et al. 1993; Teng and Apperson 2000), when the predatory mosquito Toxorhynchites rutilus (Dyar \& Knab) was present (Lounibos et al. 2001), or with increased larval densities (Teng and Apperson 2000). This advantage over A. triseriatus has also persisted in a three species assemblage with $A$. aegypti and A. albopictus in Florida (Ho et al. 1989). However, the number of field investigations have been small (Juliano 2009) and the competitive asymmetry between A. albopictus and A. triseriatus less manifested, especially in pristine woodland environments (Lounibos et al. 2001). Reduced interspecific competition (Livdahl and Willey 1991), selective consumption of A. albopictus by predators (Griswold and Lounibos 2006), and the intraguild predation by A. triseriatus (Edgerly et al. 1999) might account for the persistence of this native species in tree holes leading to a related second hypothesis that $A$. triseriatus displacement would not be as severe in less disturbed and rural areas (Lounibos et al. 2001).

Our analyses confirmed that A. albopictus invasion was accompanied by significant reductions in A. triseriatus adult populations, and demonstrated that these trends coincided in time and space. The effect was not only limited to the reduction in mosquito production, but also indicated local displacement at the spatial scales used in this study. Compared to our 2002 baseline data, the spatial extent of A. albopictus presence doubled from 36 to $72 \%$ of the study area, whereas that of A.triseriatus decreased by almost the same scale ( 89 versus $53 \%$ ). Moreover, these changes occurred at the locations where high $A$. triseriatus densities were found prior to increases in $A$. albopictus abundance, providing strong support for the first hypothesis of competitive exclusion. The observed reduction in A. triseriatus adult populations cannot be attributed to the potential confounding factors related to the climate change such as direct effects of warming temperatures on this species. Aedes triseriatus occupies an extensive geographic range in North America from Texas and Florida in the south to Quebec and Manitoba in the north (Darsie and Ward 2005) and is not expected to be directly impacted by the climatic conditions within the study area.

The hypothesis on competitive advantage of A. triseriatus in less disturbed rural areas was not supported by our data. Inherent differences in container Aedes abundance and composition existed along the urbanization gradient, however, relatively consistent through time with $A$. triseriatus experiencing similar rate of decline in urban or less disturbed rural areas. The more precipitous decline in A. triseriatus abundance in suburban (by a factor of 3-6 between 2002 and 2006-2010 time periods) rather than highly urbanized areas (by a factor of 2.5) might be explained by the greater rate of increase for A. albopictus densities in less urban areas. Interestingly, the rate of A. triseriatus decline in more rural areas where it was the most abundant was similar to that in highly urbanized areas, suggesting that this indigenous species may find its optimal habitat where it would coexist (albeit in lower numbers) with the invasive species (Juliano 1998), even in highly disturbed environments.

The decreased persistence of rural A. triseriatus might be attributed to several factors. Unlike Florida, where predators such as $T$. rutilus are an important component of the community assemblage (Ellis et al. 2006; Griswold and Lounibos 2006), the only container mosquito predator in New Jersey is T. rutilus septentrionalis (Coquillett), a temperate subspecies which occurs in lower densities and exhibits higher rates of cannibalism (Farajollahi et al. 2009; Bartlett-Healy et al. 2012). Additionally, the intraguild predation by $A$. triseriatus might not be significant in the field (Juliano and Lounibos 2005) as corroborated by the local extinctions of $A$. triseriatus identified in our dataset. However, these conclusions may be influenced by the large spatial scale used in the analysis and a finer spatial grain might provide a more nuanced picture.

In addition to $A$. albopictus, another invasive species A. japonicus has been present in our study area since the late 1990's (Peyton et al. 1999). The third hypothesis, therefore, concerned the competitive disadvantage of the native species in the presence of a second invasive is supported by a small number of studies indicating A. triseriatus as an inferior larval 
competitor to A. japonicus (Andreadis and Wolfe 2010; Alto 2011). Our study found A. japonicus wellestablished in northern New Jersey, where A. triseriatus counts were depressed compared to the rest of the state in the 2002 baseline. While this pattern in the northern study area appeared relatively stable, southern and coastal New Jersey areas experienced rapid rates of increase in A. albopictus adult abundance in 2003-2010 with a corresponding decline in A. triseriatus densities. Thus, the stabilized A. triseriatus populations in the north became the new highs co-localizing with A. japonicus clusters. In comparison, the overlaps between high counts of either of these two species with those of A. albopictus were rare. It is uncertain whether this balance will be upset by further encroachment of A. albopictus into northern New Jersey. This species is a superior competitor to A. japonicus (Armistead et al. 2008), and, in our study, A. japonicus adult populations experienced small (but significant) declines both temporally during the later stages of A. albopictus invasion (2006-2010 time period) and spatially as a displacement of high density clusters along the coast.

The slow A. albopictus intrusion into the more northern A. japonicus dominated areas may be assisted by the climatic changes that have a direct effect on the invasive Aedes mosquitoes (Juliano and Lounibos 2005). Warmer temperatures generally favor A. albopictus (Ho et al. 1989; Hanson and Craig 1995; Teng and Apperson 2000; Juliano and Lounibos 2005; Unlu and Farajollahi 2012) and lower temperatures limit the northern range of this species (Hanson and Craig 1995; Unlu and Farajollahi 2012). Precipitation may also determine the outcome of competition between A. albopictus and other Aedes species (Costanzo et al. 2005). In our study, adult A. albopictus abundance was positively associated with both high winter temperature and precipitation, which had the opposite effect on adult A. triseriatus abundance. These inexplicable negative effects on the native species contradict previous findings (Hanson and Craig 1995), and are best explained by the influence of winter weather on the populations of the invasive species, which are inversely associated with those of the native species. Warmer temperature or substantial snow cover may facilitate overwintering A. albopictus egg survival (Hanson and Craig 1995), likely resulting in increased larval densities and leading to suppressed adult A. triseriatus populations in the summer. No such relationship was found for $A$. japonicus, a temperate species with northern origins, which was positively associated with summer precipitation in this study. Wet summer conditions (e.g. year 2009, Fig. 1) may enhance A. japonicus competitive advantage over A. albopictus similarly to the relationship between the latter species and the tropical A. aegypti in Florida (Costanzo et al. 2005). However, as indicated previously by Farajollahi and Nelder (2009), the recent climate trends of warmer and wetter winters but average summer precipitation appear to favor further expansion of A. albopictus northward within our study area.

Interspecies interactions and climate change are vital for understanding population dynamics of invasive container Aedes mosquitoes and the pathogens they carry, also underscoring the importance of a strong ecological perspective for public health (Juliano and Lounibos 2005). Aedes albopictus has a greater disease transmission potential (Lounibos 2002; Weaver and Reisen 2010) and abundance compared to A. triseriatus across their range in New Jersey, especially in highly urbanized areas. Increased competition with $A$. japonicus may also lead to higher arbovirus infection rates in A. albopictus (Alto et al. 2005). Many other questions regarding the role of predation, trait-and density-mediated effects not only on ecology, but also on epidemiology of container Aedes and the pathogens vectored by these mosquito species remain unanswered (Juliano 2009). The conceptual framework for community ecology of container Aedes was largely developed in the subtropics and based on larval stages. These insights were fully validated by our study at the adult population level and in a more temperate climate with a different community. Thus, the robustness of ecological theory will allow further inquiry into the remaining questions in basic and applied science of ecological interactions, invasion biology, and public health implications.

\section{Summary}

The invasion of a stronger larval competitor, the Asian tiger mosquito (A. albopictus) was accompanied by a steep decline in the adult populations of the native A. triseriatus. These trends of increased A. albopictus populations and diminished $A$. triseriatus populations coincided in time and co-localized spatially over a large geographic area across both urban and rural locales. The competitive advantage of A. albopictus 
could be attributed almost entirely to warmer winter temperatures. The invasion of A. albopictus had a negative effect, but to a lesser degree, on another exotic mosquito, A. japonicus in the areas occupied by both species. The native $A$. triseriatus maintained higher populations in areas dominated by A. japonicus, suggesting less intense interspecific competition between these two species. This study demonstrated for the first time that interspecific interactions among larval container inhabiting Aedes can have profound effects on adult populations of these species in nature. The implications of these findings underscore the importance of a strong ecological perspective in vector biology, mosquito-borne disease epidemiology, and public health.

Acknowledgments We thank the New Jersey State Mosquito Control Commission and the intense dedication and efforts of personnel located within all 21 mosquito control programs in New Jersey and the Center for Vector Biology at Rutgers University.

Open Access This article is distributed under the terms of the Creative Commons Attribution License which permits any use, distribution, and reproduction in any medium, provided the original author(s) and the source are credited.

\section{References}

Alto BW (2011) Interspecific larval competition between invasive Aedes japonicus and native Aedes triseriatus (Diptera: Culicidae) and adult longevity. J Med Entomol 48:232-242

Alto BW, Lounibos LP, Higgs S, Juliano SA (2005) Larval competition differentially affects arbovirus infection in Aedes mosquitoes. Ecology 86:3279-3288. doi:10.1890/05-0209

Andreadis TG, Wolfe RJ (2010) Evidence for reduction of native mosquitoes with increased expansion of invasive Ochlerotatus japonicus japonicus (Diptera: Culicidae) in the northeastern United States. J Med Entomol 47:43-52

Armistead JS, Arias JR, Nishimura N, Lounibos LP (2008) Interspecific larval competition between Aedes albopictus and Aedes japonicus (Diptera: Culicidae) in northern Virginia. J Med Entomol 45:629-637

Bartlett-Healy K, Unlu I, Obenauer P, Hughes T, Healy S, Crepeau T, Farajollahi A, Kesavaraju B, Fonseca D, Schoeler G, Gaugler R, Strickman D (2012) Larval mosquito habitat utilization and community dynamics of Aedes albopictus and Aedes japonicus (Diptera: Culicidae). J Med Entomol 49:813-824. doi:10.1603/ME11031

Costanzo KS, Kesavaraju B, Juliano SA (2005) Conditionspecific competition in container mosquitoes: the role of noncompeting life-history stages. Ecology 86:3289-3295. doi:10.1890/05-0583
Darsie RF, Ward RA (2005) Identification and distribution of the mosquitoes of North America north of Mexico. University Press of Florida, Gainesville, FL

Edgerly JS, Willey MS, Livdahl T (1999) Intraguild predation among larval treehole mosquitoes, Aedes albopictus, Ae. aegypti, and Ae. triseriatus (Diptera: Culicidae), in laboratory microcosms. J Med Entomol 36:394-399

Ellis AM, Lounibos LP, Holyoak M (2006) Evaluating the longterm metacommunity dynamics of tree hole mosquitoes. Ecology 87:2582-2590. doi:10.1890/0012-9658(2006)87 [2582:ETLMDO]2.0.CO;2

Farajollahi A, Nelder MP (2009) Changes in Aedes albopictus (Diptera: Culicidae) populations in New Jersey and implications for arbovirus transmission. J Med Entomol 46:1220-1224

Farajollahi A, Kesavaraju B, Nelder MP, Crans SC, Gaugler R (2009) An unusual larval collection and survival of Orthopodomyia signifera in the presence of the predator Toxorhynchites rutilus septentrionalis. J Am Mosq Control Assoc 25:370-373. doi:10.2987/09-5878.1

Griswold MW, Lounibos LP (2006) Predator identity and additive effects in a treehole community. Ecology 87:987-995. doi:10.1890/0012-9658(2006)87[987:PIAAEI]2.0.CO;2

Hanson SM, Craig GB Jr (1995) Aedes albopictus (Diptera: Culicidae) eggs: field survivorship during northern Indiana winters. J Med Entomol 32:599-604

Ho BC, Ewert A, Chew LM (1989) Interspecific competition among Aedes aegypti, Ae. albopictus, and Ae. triseriatus (Diptera: Culicidae): larval development in mixed cultures. J Med Entomol 26:615-623

Juliano SA (1998) Species introduction and replacement among mosquitoes: interspecific resource competition or apparent competition? Ecology 79:255-268. doi:10.1890/00129658(1998)079[0255:SIARAM]2.0.CO;2

Juliano SA (2009) Species interactions among larval mosquitoes: context dependence across habitat gradients. Annu Rev Entomol 54:37-56

Juliano SA, Lounibos LP (2005) Ecology of invasive mosquitoes: effects on resident species and on human health. Ecol Lett 8:558-574

Livdahl TP, Willey MS (1991) Prospects for an invasion: competition between Aedes albopictus and native Aedes triseriatus. Science 253:189-191

Lounibos LP (2002) Invasions by insect vectors of human disease. Annu Rev Entomol 47:233-366

Lounibos LP, O'Meara GF, Escher RL, Nishimura N, Cutwa M, Nelson T, Campos RE, Juliano SA (2001) Testing predictions of displacement of native Aedes by the invasive Asian tiger mosquito Aedes albopictus in Florida, USA. Biol Invasions 3:151-166. doi:10.1023/A:1014519919099

Novak MG, Higley LG, Christianssen CA, Rowley WA (1993) Evaluating larval competition between Aedes albopictus and A. triseriatus (Diptera: Culicidae) through replacement series experiments. Environ Entomol 22:311-318

Perry JN, Winder L, Holland JM, Alston RD (1999) Red-blue plots for detecting clusters in count data. Ecol Lett 2:106-113. doi:10.1046/j.1461-0248.1999.22057.x

Peyton EL, Campbell SR, Candeletti TM, Romanowski M, Crans WJ (1999) Aedes (Finlaya) japonicus japonicus (Theobald), a new introduction into the United States. J Am Mosq Control Assoc 15:238-241 
Teng HJ, Apperson CS (2000) Development and survival of immature Aedes albopictus and Aedes triseriatus (Diptera: Culicidae) in the laboratory: effects of density, food, and competition on response to temperature. J Med Entomol $37: 40-52$

Unlu I, Farajollahi A (2012) Vectors without borders: imminent arrival, establishment, and public health implications of the
Asian bush (Aedes japonicus) and Asian tiger (Aedes albopictus) mosquitoes in Turkey. Hacetteppe J Biol Chem 40:23-36

Weaver SC, Reisen WK (2010) Present and future arboviral threats. Antiviral Res 85:328-345 